\title{
Human genetic diversity in the Japanese Archipelago: dual structure and beyond
}

\author{
Timothy A. Jinam ${ }^{1 *}$, Hideaki Kanzawa-Kiriyama ${ }^{2}$ and Naruya Saitou ${ }^{1}$ \\ ${ }^{1}$ Division of Population Genetics, National Institute of Genetics, Yata 1111, Mishima 411-8540, Japan \\ ${ }^{2}$ Department of Anthropology, National Museum of Nature and Science, \\ 4-1-1 Amakubo, Tsukuba, Ibaraki 305-0005, Japan
}

(Received 30 January 2015, accepted 9 March 2015)

\begin{abstract}
The Japanese Archipelago stretches approximately 3,000 kilometers from Hokkaido in the north to the Ryukyu Islands in the south, and has seen human activity since at least 30 thousand years ago (KYA). The Jomon period from 16 to $3 \mathrm{KYA}$ is associated with cord-marked pottery and the people at that time, who were hunter-gatherers, occupied a range of locations across the Japanese Archipelago. The Yayoi period from 3 to $1.7 \mathrm{KYA}$ saw the introduction of migrants from the Asian Continent who brought rice agriculture to the archipelago. The dual-structure model, which is based on craniofacial measurements, proposes that admixture between the Jomon and Yayoi people resulted in current-day Japanese. Subsequent genetic studies using uniparental and autosomal markers in currentday and ancient human samples are widely in support of the dual-structure model. These genetic data have also unveiled the uniqueness of the indigenous Ainu and Ryukyuan people while further demonstrating the genetic substructure within the Mainland Japanese.
\end{abstract}

Key words: Japanese Archipelago, Japanese, Ainu, Ryukyu, population genetics

\section{INTRODUCTION}

The Japanese Archipelago is made up of more than 6,000 islands that lie east of the Asian Continent. The northernmost main island, Hokkaido, is flanked by Sakhalin and the Kuril Islands of Russia, whereas the southernmost tip is made up of the Ryukyu Islands, which extend to neighboring Taiwan. Most of the approximately 120 million Japanese people reside in the four largest islands: Hokkaido, Honshu, Shikoku and Kyushu. Honshu is the largest island and can be divided into Tohoku, Kanto-Koshinetsu, Tokai-Hokuriku, Kinki and Chugoku regions (Fig. 1). The Japanese people whose ancestral lineages are originally from Honshu, Shikoku or Kyushu islands are referred to as Hondo Japanese ('mainland' in Japanese). Besides the Hondo Japanese, there are indigenous groups in the Ryukyu Islands and Hokkaido named Ryukyuan and Ainu, respectively.

Demographic events during the Jomon and Yayoi periods have left their impact on the genetic diversity of current human populations in the Japanese Archipelago. Researchers have mainly considered these two historical periods when inferring the origins of the Japanese people. This review will discuss the impact of prehistorical migration events on the genetic diversity of the Japanese, the unique characteristics of the indigenous Ryukyuan and Ainu populations, and finally the origins and genetic substructure of the Hondo Japanese. Early population genetic studies relied on either uniparental markers (mitochondrial DNA (mtDNA) and Y-chromosome) (Hammer and Horai, 1995; Horai et al., 1996) or dozens of polymorphic autosomal markers such as blood groups and red blood cell enzymes (Misawa and Hayashida, 1968; Omoto and Harada, 1972; Omoto et al., 1973). With the advancement of high-throughput genotyping and sequencing technologies, a large amount of genetic data of the Japanese has become available in projects such as HapMap (The International HapMap Consortium, 2005), Pan-Asian SNP (The HUGO Pan-Asian SNP Consortium, 2009) and the 1000 Genomes Project (1000 Genomes Project Consortium, 2012). Genetic data are not limited to existing individuals, as more ancient DNA has been successfully extracted from human remains that date back as far as the Jomon period. The availability and detailed analyses of these data will prove invaluable in forming a better understanding of the origins and history of the Japanese population. 


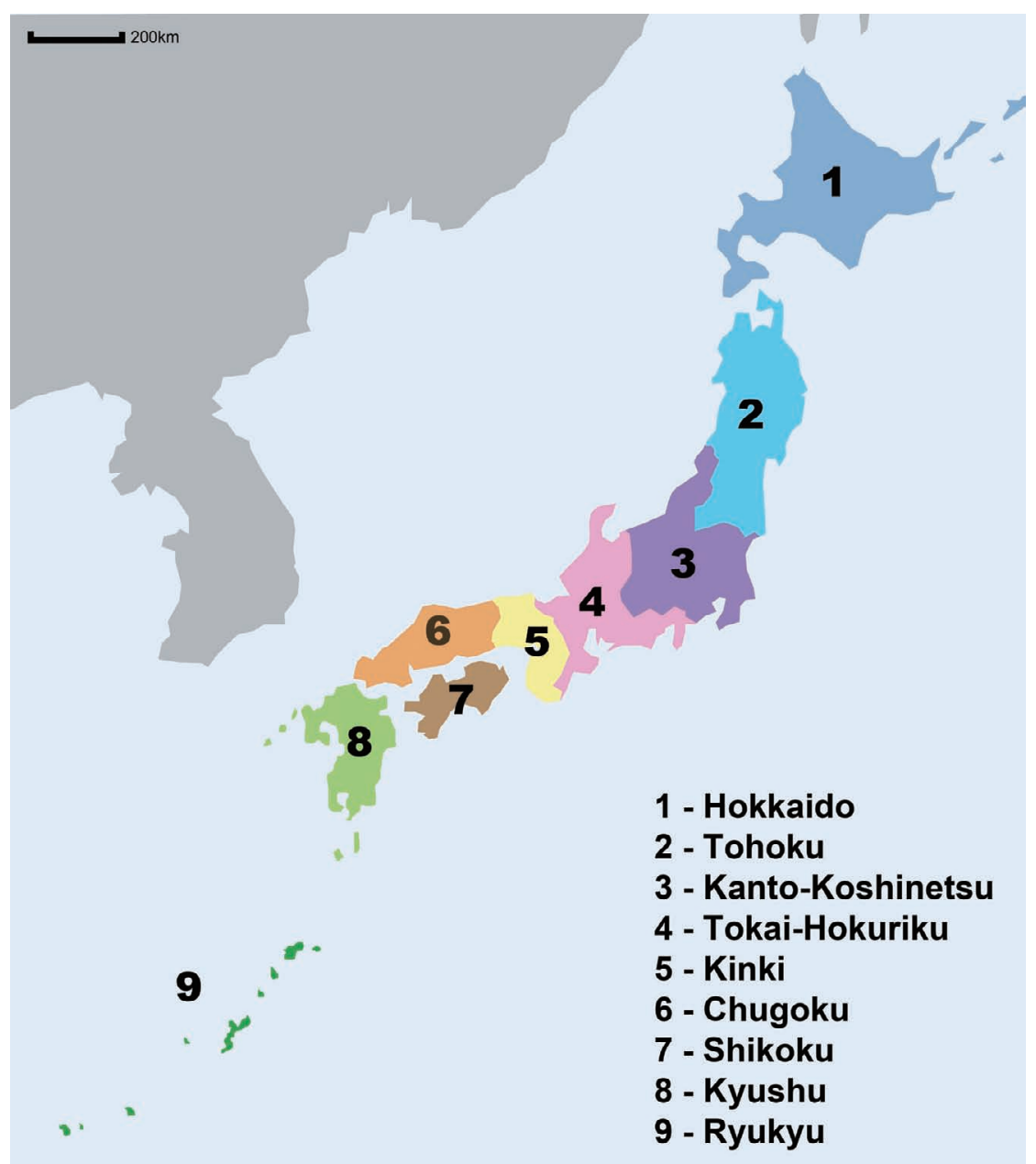

Fig. 1. Map of the Japanese Archipelago.

\section{PREHISTORY OF THE JAPANESE ARCHIPELAGO}

The Japanese Archipelago has a long history of human presence (Ono et al., 2002; Kaifu and Mizoguchi, 2011; Saitou, 2015). The earliest signs of human activity in the archipelago are the presence of stone tools that date back to 30 thousand years ago (KYA) (Imamura, 1996). The oldest human remains found were also dated to approximately $30 \mathrm{KYA}$, corresponding to the upper Paleolithic period. The Ryukyu Islands, in particular, yielded several of these old skeletal remains. The oldest human fossils found in Japan are from Yamashita-cho Cave on Okinawa Island, and carbon-14 dating suggested an age of 32 KYA (Suzuki, 1983). Other sites such as Pinza-abu on Miyako Island and Minatogawa Fissure on Okinawa Island yielded human remains with ages that range from 18 to 26 KYA (Kobayashi, 1974; Department of Education, Okinawa Prefectural Government, 1985; Baba and Narasaki, 1991). Most recently, a site in Shiraho-Saonetabaru cave on Ishigaki Island yielded human remains dating to $20 \mathrm{KYA}$ (Nakagawa et al.,
2010). In Honshu Island, the oldest remains were found in Mikkabi and Hamakita in Shizuoka prefecture, dating to 7 to 14 KYA (Suzuki, 1962; Matsu'ura and Kondo, 2001). These archeological findings show that there was already a substantial human presence in the Japanese Archipelago during the Paleolithic period. However, it remains unclear whether the Paleolithic people that already inhabited the Japanese Archipelago at that time were the direct ancestors of the Jomon people. Comparisons of tooth measurements show substantial difference between the Paleolithic Minatogawa human from Okinawa and Jomon samples (Suwa et al., 2011), and may imply a discontinuity between the Paleolithic and Jomon people.

The Jomon period from 16 to $3 \mathrm{KYA}$ takes its name from the cord-marked pottery typically found in that time period. The means of sustenance for the Jomon people was primarily through hunting and gathering, and agriculture was rudimentary and limited. The Jomon people were distributed across the Japanese Archipelago, based on the artifacts (Habu, 2004) and human remains found. The skeletal remains show a marked difference 
between the Jomon people and present-day Hondo Japanese. Similarities in the cranial measurements of Jomon and Polynesians (Hanihara, 1991) led to the hypothesis that the Jomon people originated from Southeast Asia.

The morphological structure of the Jomon was also found to be close to the Ainu and Ryukyuans (Yamaguchi and Dodo, 1980), suggesting that these two groups retain more Jomon ancestry than the Hondo Japanese. These ancient Jomon remains provided priceless data not only for physical anthropologists, but also for geneticists. Although a large majority of the DNA extracted from these ancient remains was derived from environmental microorganisms and other contaminants, the small percentage of endogenous DNA that was extracted still yielded useful and important data. Early studies of ancient DNA tended to focus on mtDNA, mainly due to larger copy numbers of the molecule that remained in the ancient samples compared to the nuclear genome. mtDNA extracted from Jomon samples shows enrichment for haplogroups N9b and M7a (Adachi et al., 2011; Kanzawa-Kiriyama et al., 2013). These two haplogroups are rarely found in other populations except in the Japanese Archipelago, which further supports the idea of Jomon ancestry in modern Japanese. Interestingly, haplogroup N9b is also found at high frequencies in the Udegey, a group in southern Siberia (Tajima et al., 2004), suggesting that the Jomon may have genetic links with populations from Northeast Asia. For prehistoric samples, most of the ancient DNA was extracted from Jomon remains excavated from the Hokkaido and Tohoku areas (Fig. 1), where the lower temperatures and humidity in these northern regions may have played a part in limiting DNA degradation in the ancient human remains. However, as DNA extraction and sequencing methods keep improving, we anticipate that ancient DNA can still be extracted from poorly preserved samples and enable genetic analyses of Jomon samples from a wider distribution in Japan. These kinds of improvements will help address issues such as whether there was already population substructure during the Jomon period and the extent of Jomon genetic contributions to the modern Japanese. Combined analyses with other ancient DNA from the Asian continent ( $\mathrm{Fu}$ et al., 2013) may also help to answer questions regarding the origins of the Jomon people.

The Jomon period was followed by what is known as the Yayoi period, which lasted from approximately 3 to 1.7 KYA. The starting date of the Yayoi period is still debatable: previous estimates started from 2.5 KYA (Imamura, 1996), while recent improvements in dating methods have suggested a much older estimate, up to $3.2 \mathrm{KYA}$ (Fujio, 2011). This period is largely known as the time when agriculture, in particular rice, was introduced to the Japanese Archipelago. Although the exact geographical origin of the Yayoi people is unclear, they are believed to have migrated from the Asian mainland through the Korean peninsula and into the Japanese Archipelago via the Kyushu and/or Chugoku regions (Fig. 1). Bone morphological structure shows that the Yayoi people were markedly different from the preceding Jomon people (Hanihara, 1991; Dodo et al., 1992). Unfortunately, studies of ancient DNA samples from the Yayoi period (e.g., Oota et al., 1995) are not as extensive as those of Jomon samples, but this should change in the future. Besides introducing rice agriculture, the Yayoi migrants also brought new technologies and tools (Imamura, 1996); but just as importantly, they made a significant contribution the genetic makeup of the present-day Japanese.

The origin of the current Hondo Japanese population was inferred based on interactions between the Yayoi migrants and the Jomon people who were already present in the Japanese Archipelago at that time. Currently, the widely accepted model for the origin of Hondo Japanese is the admixture model, also known as the dual-structure model (Hanihara, 1991). According to this model, Hondo Japanese are the result of admixture between the ancestral Yayoi and Jomon people (Fig. 2). The current Ainu and Ryukyuan groups are believed to retain more Jomon components, based on morphological measurements. Alternative models include the replacement theory, which posits that the Yayoi migrants totally displaced the Jomon populations, and the transformation theory, in which the early Paleolithic humans continually evolved into current Hondo Japanese with minimal gene flow from Yayoi migrants (Suzuki, 1963; Mizoguchi, 1986). As discussed in the later sections, the admixture model is currently the most widely accepted model and is well supported by genetic data.

\section{THE INDIGENOUS GROUPS OF JAPAN}

The Ainu and Ryukyuan populations are indigenous groups who now mostly reside in Hokkaido and the

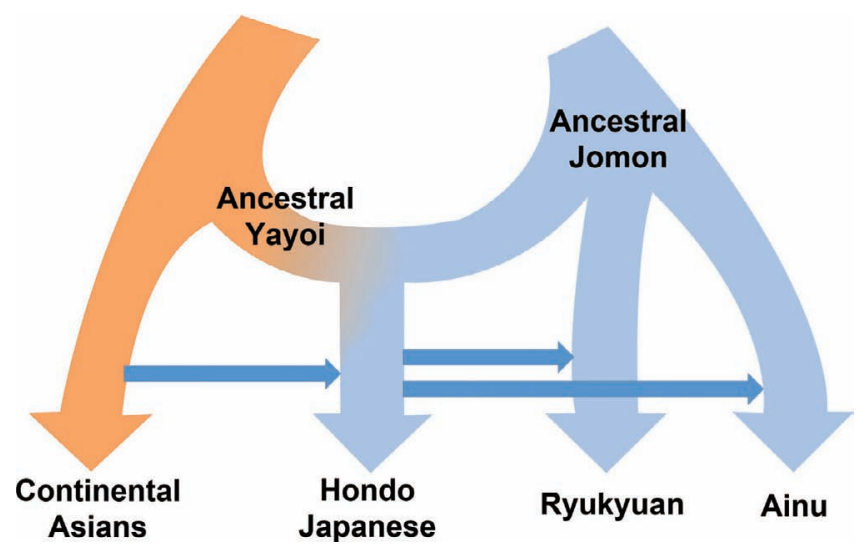

Fig. 2. Model representing the origins of human populations in the Japanese Archipelago. Horizontal blue arrows indicate recent admixture events between the different groups. 
Ryukyu Islands, respectively. Because of similarities in their cranial and skeletal morphologies with those of the Jomon people (Yamaguchi and Dodo, 1980; Hanihara, 1991), they are thought to be the more direct descendants of the Jomon people than the Mainland Japanese. In fact, early anthropologists already noticed that the similarities between the Ainu and Ryukyuans might be due to shared ancestry (von Baelz, 1911). The Ainu in particular exhibit physical features that are distinct from the Hondo Japanese, leading to various hypotheses regarding their origins, including genetic links to West Eurasians. The Ainu have traditionally been associated with a hunting-gathering lifestyle that is common to other populations surrounding the Sea of Okhotsk, such as the Nivkhi in Sakhalin. Rather than being an isolated group, the Ainu most likely experienced cultural and genetic exchange with their neighboring populations. A study of dental measurements showed similarities between the Ainu and the Okhotsk culture people from the $5^{\text {th }}$ to $12^{\text {th }}$ century A.D. (Hanihara, 2010), while mtDNA analysis showed phylogenetic clustering of the Ainu, Nivkhi and Okhotsk people (Adachi et al., 2011). A study of the $A B C C 11$ gene that is responsible for ear wax type further suggests gene flow from Northeast Asia (possibly by Okhotsk people) into the Ainu in Hokkaido (Sato et al., 2009).

Early mtDNA analysis of the Ainu using a limited number of restriction enzymes showed similarities with Hondo Japanese (Harihara et al., 1986), but later studies showed high affinities between the Ainu and Nivkhi from Sakhalin (Tajima et al., 2004), supporting previous suggestions of genetic influence from North Eurasian populations. Analysis using another uniparental marker, the Ychromosome, showed the presence of haplogroup D-M125 in the Ainu. This Y-haplogroup is endemic to the Japanese Archipelago and is found in high frequencies in the Ainu and Ryukyuans (Tajima et al., 2004; Hammer et al., 2006), further adding support for the idea of shared ancestry between these two groups. This was further supported by a genome-wide single nucleotide polymorphism (SNP) study that showed the Ainu and Ryukyuans cluster with $100 \%$ bootstrap probability on the phylogenetic tree (Jinam et al., 2012). Furthermore, autosomal SNP data also revealed signs of recent admixture between the Ainu and Hondo Japanese (Jinam et al., 2015).

The Ryukyu Islands can be geographically classified into four main clusters, but the most populated island is Okinawa Island. Archeological findings suggest that there were different cultures that developed in the northern part of the Ryukyu Islands (closer to Kyushu and Honshu) and the southern part (closer to Taiwan) (Asato, 2003). Previous genetic studies mostly focused on individuals from Okinawa Island and found that they have high genetic similarities with the Ainu in Hokkaido, even though these two groups are geographically very distant (Omoto, 1995; Omoto and Saitou, 1997). Genome-wide SNP studies show that the Okinawans form a distinct cluster from the Hondo Japanese (Yamaguchi-Kabata et al., 2008), while a more detailed genetic survey of individuals from three main islands in the Ryukyu cluster found differentiation between the island groups that was attributed to genetic drift (Sato et al., 2014).

However, none of those genetic studies demonstrated any links between the Ainu and Ryukyuans and current Southeast Asian populations, which runs counter to the hypothesis derived from archeological and anthropological data (Hanihara, 1991). It may be possible that any shared genetic loci between the indigenous Japanese and Southeast Asians have become 'hidden away' in the genome due to recombination, assuming that these two groups diverged a long time ago. A more detailed sequence analysis and good-quality ancient DNA from Jomon period samples should contribute to solving this particular conundrum.

\section{ORIGINS OF THE HONDO JAPANESE AND THEIR GENETIC SUBSTRUCTURE}

Previous studies employed genetic markers such as mitochondrial, Y-chromosomal and autosomal DNA to tackle the issues surrounding the origins of the Japanese. Support for the dual-structure hypothesis included studies based on mtDNA sequences (Horai et al., 1996; Tanaka et al., 2004), Y-chromosomal SNPs and short tandem repeat polymorphisms (Hammer et al., 2006). Analyses involving classical protein markers led to partial support for the dual-structure model, supporting the shared ancestry of the Ainu and Ryukyuans dating back to the Jomon people, but found no close relationship between them and Southeast Asians (Omoto and Saitou, 1997).

A genome-wide SNP study of three Japanese groups (Hondo Japanese mostly from Tokyo, Ainu and Ryukyuan) (Jinam et al., 2012) adds support to the dual-structure model. Phylogenetic tree analysis shows that the Hondo Japanese are located between an Ainu-Ryukyuan cluster and continental Asians, suggesting that they are admixed between these two population clusters. A follow-up to that study used a formal test for admixture (Patterson et al., 2012) to show that the Hondo Japanese are indeed the result of admixture between the ancestors of the Ainu and Han Chinese or Korean: the Jomon and Yayoi people, respectively. Furthermore, they estimated the proportion of Jomon component in the Hondo Japanese to be approximately $18 \%$ and that the admixture event occurred at least 1.4 KYA (Jinam et al., 2015). Other studies have tried to estimate the proportion of Jomon ancestry in the Japanese population. Using Y-chromosomal markers in the Ainu, Ryukyuan and Hondo Japanese from sev- 
eral locations, Rasteiro and Chikhi (2009) estimated the Jomon component in the Hondo Japanese using likelihood-based methods and reported a range of $20 \%$ to $50 \%$. A study by $\mathrm{He}$ et al. (2012) used approximately 50,000 autosomal SNPs to estimate a value of $23 \%$ to $40 \%$ Jomon component in the Hondo Japanese. These studies generally agree with the dual-structure model and add further details such as admixture proportions, but the dual-structure model alone may not be sufficient to explain the genetic substructure observed in Hondo Japanese.

Using more than 500,000 SNP data in 7,003 Japanese throughout the Japanese Archipelago, YamaguchiKabata et al. (2008) showed that the differentiation between Hondo Japanese from different regions was small (Fst values ranged from 0.00023-0.00077), yet they can still be distinguished in principal component analysis plots. Between the different Hondo Japanese clusters, the highest amount of differentiation was observed between Japanese from Tohoku and Tokai-Hokuriku (Fig. 1). Unfortunately, this study did not include Japanese from the Chugoku and Shikoku areas, which are geographically closer to the Korean peninsula. Another study sampled a wider coverage of individuals throughout Japan but used five highly polymorphic immune-related genes. The authors showed that the Japanese from Shikoku and Hokuriku are differentiated from other Hondo Japanese (Nakaoka et al., 2013). It is clear from these studies that the Japanese people are not homogeneous, but to establish whether the observed differentiation can be explained purely by genetic drift or other migration waves will require further study.

\section{CONCLUSION}

Genetic analyses of both current populations and ancient remains has greatly enriched our understanding of the history and diversity of human populations in the Japanese Archipelago. In general, genetic data strongly support the dual-structure model proposed by Hanihara (1991) whereby the Hondo Japanese are the result of admixture between the Jomon and Yayoi ancestral populations (Fig. 2). The indigenous Ainu and Ryukyuan populations retain a genetic identity that most likely traces back to Jomon ancestors, while at the same time show indications of recent admixture with the Hondo Japanese (Jinam et al., 2015). Some questions remain unanswered, however, such as the origins of the Jomon people and the genetic affinities of the Yayoi people. These questions can hopefully be addressed by more comprehensive and expansive ancient DNA studies. Large-scale genetic surveys have also unearthed genetic substructure within the Hondo Japanese (YamaguchiKabata et al., 2008; Nakaoka et al., 2013). Such studies are of interest not only to population geneticists and anthropologists, but also to medical geneticists who may utilize such data to improve diagnosis and personalized treatment of diseases. The genetic substructure in the Hondo Japanese also hints at a more complex model of human migrations and interactions than the dualstructure model implies. Future efforts to sample Japanese groups not represented in previous genetic studies will greatly benefit our understanding of human population history in the Japanese Archipelago.

\section{REFERENCES}

1000 Genomes Project Consortium, Abecasis, G. R., Auton, A., Brooks, L. D., DePristo, M. A., Durbin, R. M., Handsaker, R. E., Kang, H. M., Marth, G. T., McVean, G. A., et al. (2012) An integrated map of genetic variation from 1,092 human genomes. Nature 491, 56-65.

Adachi, N., Shinoda, K., Umetsu, K., Kitano, T., Matsumura, H., Fujiyama, R., Sawada, J., and Tanaka, M. (2011) Mitochondrial DNA analysis of Hokkaido Jomon skeletons: remnants of archaic maternal lineages at the southwestern edge of former Beringia. Am. J. Phys. Anthropol. 146, 346-360.

Asato, S. (2003) Prehistory and proto-history in the Ryukyu island chain. History of Okinawa Prefecture 2: archaeology. Okinawa Prefecture Board of Education, Naha. [in Japanese]

Baba, H., and Narasaki, S. (1991) Minatogawa Man, the oldest type of modern Homo sapiens in East Asia. The Quaternary Research 30, 221-230.

von Baelz, E. (1911) Die Riu-Kiu-Insulaner, die Aino und andere kaukasier-ahnliche Reste in Ostasien. Korres. Blatt. Dtsch. Ges. Anthrop. Ethnol. Urgesch. 42, 187-191. [in German]

Department of Education, Okinawa Prefectural Government (ed.) (1985) Pinza-Abu: Reports on excavation of the PinzaAbu Cave. Department of Education, Okinawa Prefectural Government, Naha. [in Japanese]

Dodo, Y., Ishida, H., and Saitou, N. (1992) Population history of Japan: a cranial nonmetric approach. In: The Evolution and Dispersal of Modern Humans in Asia (eds.: Akazawa, T., Aoki, K., and Kimura, T.), pp. 479-492. Hokusen-sha, Tokyo.

Fu, Q., Meyer, M., Gao, X., Stenzel, U., Burbano, H. A., Kelso, J., and Pääbo, S. (2013) DNA analysis of an early modern human from Tianyuan Cave, China. Proc. Natl. Acad. Sci. USA 110, 2223-2227.

Fujio, S. (2011) Shin Yayoi Jidai. Yoshikawa Koubunkan, Tokyo. [in Japanese]

Habu, J. (2004) Ancient Jomon of Japan. Cambridge University Press, New York.

Hammer, M. F., and Horai, S. (1995) Y chromosomal DNA variation and the peopling of Japan. Am. J. Hum. Genet. 56, 951-962.

Hammer, M. F., Karafet, T. M., Park, H., Omoto, K., Harihara, S., Stoneking, M., and Horai, S. (2006) Dual origins of the Japanese: common ground for hunter-gatherer and farmer Y chromosomes. J. Hum. Genet. 51, 47-58.

Hanihara, K. (1991) Dual structure model for the population history of the Japanese. Japan Rev. 2, 1-33.

Hanihara, T. (2010) Metric and nonmetric dental variation and the population structure of the Ainu. Am. J. Hum. Biol. 22, 163-171.

Harihara, S., Hirai, M., and Omoto, K. (1986) Mitochondrial DNA polymorphism in Japanese living in Hokkaido. Jpn. J. Hum. Genet. 31, 73-83. 
He, Y., Wang, W. R., Xu, S., and The HUGO Pan-Asian SNP Consortium (2012) Paleolithic Contingent in Modern Japanese: Estimation and Inference using Genome-Wide data. Sci. Rep. 2, 335.

Horai, S., Murayama, K., Hayasaka, K., Matsubayashi, S., Hattori, Y., Fucharoen, G., Harihara, S., Park, K. S., Omoto, K., and Pan, I. H. (1996) mtDNA polymorphism in East Asian Populations, with special reference to the peopling of Japan. Am. J. Hum. Genet. 59, 579-590.

The HUGO Pan-Asian SNP Consortium (2009) Mapping human genetic diversity in Asia. Science, 326, 1541-1545.

Imamura, K. (1996) Prehistoric Japan: New Perspectives on Insular East Asia. University of Hawaii Press, Honolulu.

The International HapMap Consortium (2005) A haplotype map of the human genome. Nature 437, 1299-1320.

Jinam, T., Nishida, N., Hirai, M., Kawamura, S., Oota, H., Umetsu, K., Kimura, R., Ohashi, J., Tajima, A., Yamamoto, T., et al. (2012) The history of human populations in the Japanese Archipelago inferred from genome-wide SNP data with a special reference to the Ainu and the Ryukyuan populations. J. Hum. Genet. 57, 787-795.

Jinam, T. A., Kanzawa-Kiriyama, H., Inoue, I., Tokunaga, K., Omoto, K., and Saitou, N. (2015) Unique characteristics of the Ainu population in Northern Japan. J. Hum. Genet. [Epub ahead of print]

Kaifu, Y., and Mizoguchi, Y. (2011) Preface to the Special Issue: New studies on early modern humans from Okinawa, South Japan. Anthropol. Sci. 119, 97-98.

Kanzawa-Kiriyama, H., Saso, A., Suwa, G., and Saitou, N. (2013) Ancient mitochondrial DNA sequences of Jomon teeth samples from Sanganji, Tohoku district, Japan. Anthropol. Sci. 121, 89-103.

Kobayashi, H., Hirose, Y., Sugino, M., and Watanabe, N. (1974) TK-99. Minatogawa. Radiocarbon 16, 384.

Matsu'ura, S., and Kondo, M. (2001) Dating of the Mikkabi Human Remains from Japan. Anthropol. Sci. 109, 275288.

Misawa, S., and Hayashida, Y. (1968) On the blood groups among the Ainu in Shizunai, Hokkaido. Proc. Japan Acad. 44, 83-88.

Mizoguchi, Y. (1986) Contributions of prehistoric Far East populations to the population of modern Japan: A Q-mode path analysis based on cranial measurements. In: Prehistoric Hunter-Gatherers in Japan: New Research Methods. (eds.: Akazawa, T., and Aikens, C.), pp. 107-136. University of Tokyo Press, Tokyo.

Nakagawa, R., Doi, N., Nishioka, Y., Nunami, S., Yamauchi, H., Fujita, M., Yamazaki, S., Yamamoto, M., Katagiri, C., Mukai, H., et al. (2010) Pleistocene human remains from Shiraho-Saonetabaru Cave on Ishigaki Island, Okinawa, Japan, and their radiocarbon dating. Anthropol. Sci. 118, 173-183.

Nakaoka, H., Mitsunaga, S., Hosomichi, K., Shyh-Yuh, L., Sawamoto, T., Fujiwara, T., Tsutsui, N., Suematsu, K., Shinagawa, A., Inoko, H., et al. (2013) Detection of ancestry informative HLA alleles confirms the admixed origins of Japanese population. PLoS One 8, e60793.

Omoto, K. (1995) Genetic diversity and the origins of the "Mongoloids." In: The Origin and Past of Modern Humans as Viewed from DNA. (eds.: Brenner, S., and Hanihara, K.), pp. 92-109. World Scientific, Singapore and London.

Omoto, K., and Harada, S. (1972) The distribution of polymorphic traits in the Hidaka Ainu. II. Red cell enzyme and serum protein groups. J. Fac. Sci. Univ. Tokyo, V, IV 2, 171-211.
Omoto, K., and Saitou, N. (1997) Genetic origins of the Japanese: a partial support for the dual structure hypothesis. Am. J. Phys. Anthropol. 102, 437-446.

Omoto, K., Ishizaki, K., Harada, S., Akaishi, S., Kudo, T., and Takahashi, K. (1973) The distribution of serum protein and red cell enzyme types among blood donors of Okinawa Is., the Ryukyus. J. Anthrop. Soc. Nippon 81, 159-173.

Ono, A., Sato, H., Tsutsumi, T., and Kudo, Y. (2002) Radiocarbon dates and archaeology of the late Pleistocene in the Japanese Islands. Radiocarbon 44, 477-494.

Oota, H., Saitou, N., Matsushita, T., and Ueda, S. (1995) A genetic study of 2,000-year-old human remains from Japan using mitochondrial DNA sequences. Am. J. Phys. Anthropol. 98, 133-145.

Patterson, N., Moorjani, P., Luo, Y., Mallick, S., Rohland, N., Zhan, Y., Genschoreck, T., Webster, T., and Reich, D. (2012) Ancient admixture in human history. Genetics 192, 10651093.

Rasteiro, R., and Chikhi, L. (2009) Revisiting the peopling of Japan: an admixture perspective. J. Hum. Genet. 54, 349354.

Saitou, N. (2015) History of Japanese Archipelago people. Iwanami Shoten, Tokyo. [in Japanese]

Sato, T., Amano, T., Ono, H., Ishida, H., Kodera, H., Matsumura, H., Yoneda, M., and Masuda, R. (2009) Allele frequencies of the $A B C C 11$ gene for earwax phenotypes among ancient populations of Hokkaido, Japan. J. Hum. Genet. 54, 409413.

Sato, T., Nakagome, S., Watanabe, C., Yamaguchi, K., Kawaguchi, A., Koganebuchi, K., Haneji, K., Yamaguchi, T., Hanihara, T., Yamamoto, K., et al. (2014) Genome-wide SNP analysis reveals population structure and demographic history of the Ryukyu Islanders in the southern part of the Japanese archipelago. Mol. Biol. Evol. 31, 2929-2940.

Suwa, G., Fukase, H., Kono, R. T., Kubo, D., and Fujita, M. (2011) Mandibular tooth root size in modern Japanese, prehistoric Jomon, and Late Pleistocene Minatogawa human fossils. Anthropol. Sci. 119, 159-171.

Suzuki, H. (1962) Human skeletal remains of Mikkabi man. J. Anthrop. Soc. Nippon 70, 1-20. [in Japanese]

Suzuki, H. (1963) Skeletal Bones of the Japanese People. Iwanami Shoten, Tokyo.

Suzuki, H. (1983) The Yamashita-cho man: a late Pleistocene infantile skeleton from the Yamashita-cho Cave (Okinawa). Bulletins et Mémoires de la Société d'Anthropologie de Paris, Série 13, 81-87.

Tajima, A., Hayami, M., Tokunaga, K., Juji, T., Matsuo, M., Marzuki, S., Omoto, K., and Horai, S. (2004) Genetic origins of the Ainu inferred from combined DNA analyses of maternal and paternal lineages. J. Hum. Genet. 49, 187-193.

Tanaka, M., Cabrera, V. M., González, A. M., Larruga, J. M., Takeyasu, T., Fuku, N., Guo, L. J., Hirose, R., Fujita, Y., Kurata, M., et al. (2004) Mitochondrial genome variation in eastern Asia and the peopling of Japan. Genome Res. 14, 1832-1850.

Yamaguchi, B., and Dodo, Y. (1980) Genealogy of the prehistoric population of Hokkaido. Kyodo to Kagaku, 73-80, 183190. [in Japanese]

Yamaguchi-Kabata, Y., Nakazono, K., Takahashi, A., Saito, S., Hosono, N., Kubo, M., Nakamura, Y., and Kamatani, N. (2008) Japanese population structure, based on SNP genotypes from 7003 individuals compared to other ethnic groups: effects on population-based association studies. Am. J. Hum. Genet. 83, 445-456. 